\title{
Inferentialist Truth Pluralism
}

\author{
Herman Veluwenkamp ${ }^{1,2}$ (D)
}

Accepted: 29 November 2020 / Published online: 3 February 2021

(C) The Author(s) 2021

\begin{abstract}
Metasemantic inferentialism has gained popularity in the last few decades. Traditionally, inferentialism is combined with a deflationary attitude towards semantic terms such as truth and reference, i.e., many inferentialists hold that when we use these semantic terms we do not purport to refer to substantive properties. This combination makes inferentialism attractive for philosophers who see themselves as antirealists. Although the attractions of combining inferentialism and deflationism are easy to see, deflationism is also a controversial position. For one, deflationists maintain that truth is an insubstantive property, but it is not altogether clear what an insubstantive property is. Secondly, as deflationists maintain that truth does not play an explanatory role, it is incompatible with the position that truth can explain the normativity of truth talk. Given that deflationism faces these objections, it would be preferable if the success of inferentialism did not depend on the deflationist's ability to respond to these objections. I argue that someone attracted to inferentialism for its ability to accommodate antirealist intuitions about a domain (e.g. morality) is not committed to deflationism about truth. More specifically, I will show that inferentialism combined with a straightforward account of inferentialist truth-conditions is compatible with a version of truth pluralism. I call this position Inferentialist Truth Pluralism.
\end{abstract}

Keywords Inferentialism · Deflationism · Truth pluralism · Metasemantics · Conceptual role semantics $\cdot$ Minimalism

\section{Introduction}

Metasemantic inferentialism has gained popularity in the last few decades. The term 'inferentialism' was introduced by Robert Brandom but is now widely used for the position that to have meaning is to be governed by inferential or conceptual rules. Traditionally, inferentialism is combined with a deflationary attitude towards semantic terms such as truth and reference, i.e., many inferentialists hold that when we use these semantic terms we do not

Herman Veluwenkamp

h.m.veluwenkamp@tudelft.nl

1 Faculty of Philosophy, University of Groningen, Groningen, Netherlands

2 Section Ethics/Philosophy of Technology, Faculty Technology Policy and Management, Delft University of Technology, Delft, Netherlands 
purport to refer to substantive properties. ${ }^{1}$ This combination makes inferentialism attractive for philosophers who see themselves as antirealists.

The attractions of combining inferentialism and deflationism are easy to see. It allows the inferentialist to retain its use-based approach to meaning, without the need to adopt an epistemic notion of truth for all domains of discourse. ${ }^{2}$ However, despite its attractions, deflationism is also a controversial position. For one, deflationists maintain that truth is an insubstantive property, but it is not altogether clear what an insubstantive property is. Secondly, as deflationists maintain that truth does not play an explanatory role, it is incompatible with the position that truth can explain the normativity of truth talk. Given that deflationism faces these objections, it would be preferable if the success of inferentialism did not depend on the deflationist's ability to respond to these objections.

For this reason, I will argue that someone attracted to inferentialism for its ability to accommodate antirealist intuitions about a domain (e.g. morality) is not committed to deflationism about truth. More specifically, I will show that inferentialism combined with a straightforward account of inferentialist truth-conditions is compatible with a version of truth pluralism. I call this position Inferentialist Truth Pluralism.

\section{Inferentialism}

Philosophers of language can be roughly said to distinguish two different approaches to meaning (Loar 2006). The first approach takes meaning to be fundamentally a matter of representation. The second approach sees meaning primarily in terms of how that expression is used. These approaches are typically called representationalist and use theories of meaning. Although it is possible to think that meaning in one domain is a matter of representation, while it is a matter of use in another, these local theories of meaning are notoriously problematic. Geach (1965) and Searle (1962) have argued that local theories, such as metaethical expressivism, have a problem explaining why claims in one domain are semantically so similar to claims in other domains, while their meaning is determined in fundamentally different ways (see also Chrisman 2011). In this paper I will therefore be talking about theories of meaning that operate globally.

In this paper I am concerned with philosophers who are attracted to inferentialism because they have antirealist intuitions about a specific domain of discourse. I take antirealism to be a metaphysical position. The claim that one is an antirealist about domain D comes down to the denial of the thesis that properties, facts, objects, relations or events of type D exist mind-independently (in the relevant sense). So someone who is a moral antirealist believes that there are no mind-independent moral properties, facts, objects, relations or events. ${ }^{3}$

One of the important versions of the use theory of meaning is Brandom's inferentialism. The inferentialist's main claim is that the meaning of expressions is determined by their inferential role in the game of giving and asking for reasons (Brandom 1994, 2000). The

\footnotetext{
${ }^{1}$ Inferentialists adopt different versions of alethic deflationism. Brandom Brandom (1994) defends prosententialism, while Michael Williams Williams (2010) uses Paul Horwich's minimalism (Horwich 1999, 2000). In this paper I do not distinguish between these different versions of deflationism.

${ }^{2}$ See also Williams Williams (2010)

${ }^{3}$ Antirealism about a domain is therefore compatible with cognitivism about that domain. Moreover, on this use of antirealism, Kantian constitutivists such as Korsgaard and O'Neill $(1996,2009)$ also classify as antirealists.
} 
inferential role tells us what we are committed to when making an utterance, and it tells us what expressions we are entitled to when someone else utters an expression. Simplifying a little, we can say that the inferential role consists of material inferences in which the expression can function as a premise or as a conclusion. The term "material inference" is a term of art that Brandom uses to indicate that the inferences are non-monotonically valid (i.e., we can add premises to a valid material inference to make it invalid; something that is not the case with formally valid inferences). ${ }^{4}$ Let us look at an example. Suppose that someone who grasps the meaning of the predicate "is a bird" is committed to the following linguistic moves:

" $x$ is a bird" $\rightarrow$ " $x$ can fly"

" $x$ is a bird" $\rightarrow$ " $x$ has wings and feathers"

Let $\mathrm{X} \rightarrow \mathrm{Y}$ mean that if someone utters that $\mathrm{X}$, then she ought to accept that $\mathrm{Y}$. So if someone utters that something is a bird, then she ought to accept the utterance that it can fly. If she is not willing to accept that it can fly, she has to give reasons why this is so (for example, because it is a penguin). Moreover, if we are engaged in a conversation, and I say that something is a bird, I thereby license you to utter that it has wings and feathers. When I later challenge your statement that the object has wings and feathers, you can respond by pointing out that I maintained that it was a bird.

For inferentialists such as Brandom, all meaningful terms derive their meaning from their place in an inferential network of utterances. In the example above, we saw that both the premise and the conclusion of the inferences consist of sentences (as opposed to nonlinguistic phenomena, such as states of affairs). Some terms have their meaning determined by a set of material inferences that all have this feature. For these terms we can say that they stay within the language game. We can borrow some terminology from earlier use theorists and say that these terms have their meaning determined by a narrow inferential role.

Following Brandom, let us call the position that all inferential roles are narrow in this sense hyperinferentialism. Although this position is consistent, it is doubtful that hyperinferentialism is correct. It seems that there are domains of discourse where the meaning of terms is determined by something more than narrow inferential roles. Brandom formulates this worry as follows:

The meaning of 'red' is not just a matter of what other concepts its applicability is properly inferrable from (e.g., scarlet), and the applicability of what other concepts is properly inferrable from its applicability (e.g., colored), nor of the applicability of what other concepts preclude its applicability (e.g., green or multiple of 3). Its noninferential applicability to red things is also an essential propriety of the use of the concept red: one that must accordingly be underwritten by any adequate account of the meaning or content expressed by the use of the word 'red'. Brandom (2007, p. 657)

So if this is correct, we need to think of material inferences that also allow non-linguistic phenomena as premise or conclusion. Based on the example above, we can sketch the following material inferences for the predicate "is red":

" $x$ is red" $\rightarrow$ " $x$ is colored"

" $x$ is scarlet" $\rightarrow$ " $x$ is red"

${ }^{4}$ For a discussion of the empirical adequacy of non-monotonic logics, see Dutilh Novaes and Veluwenkamp (2017). 
" $x$ is red" $\rightarrow$ " $x$ is not green"

red things $\rightarrow$ " $x$ is red"

The first three inferences are, just as we saw earlier, inferences that stay within the language game. The last one, however, refers to a non-linguistic phenomenon, i.e., red things. If Brandom is correct, and I think that he is, some parts of our language do not have their meaning determined by a narrow inferential role. ${ }^{5}$ We can call the inferential roles that consist in part of non-linguistic elements, wide inferential roles. The position that allows for both narrow and wide inferential roles is called strong inferentialism (Brandom 2007, p. 657). For brevity, let us use the term narrow concept for a concept whose content is determined only by narrow inferential roles and wide concept for a concept whose content is determined by at least one wide inferential role.

I aim to show in this paper that inferentialism is compatible with inflationism, the position that truth is a substantive property that plays an explanatory role, without losing the attractions of inferentialism. But let me first say something about the relation between inferentialism and deflationism.

\section{Deflationism and Some Challenges}

When inferentialists take a stance regarding truth, they often combine their position with a deflationist account of truth. Brandom (1994), for example, who can be seen as the founding father of inferentialism, adopts a prosentential theory of truth (which is a version of deflationism). But other inferentialists who adopt deflationism include (Tiefensee 2016; Warren 2015; Price et al. 2013; Williams 2010). Some inferentialists already adopt a substantive account of truth (e.g., Wedgwood 2001, 2007, 2017; Enoch 2011). However, these philosophers are typically not motivated by antirealist intuitions. Ralph Wedgwood and David Enoch, for example, do not have a problem with accepting moral properties in their ontology. Their goal is to show that inferentialism is compatible with moral realism. Instead, I try to show that inferentialists with antirealist intuitions about a specific domain of discourse (such as morality) are not committed to deflationism.

Many inferentialists are attracted to deflationism because of a discontent with the usual substantial theories of truth. In many domains of discourse, truth is most plausibly approached as correspondence, while other domains seem to require a more epistemic, or antirealist, approach to truth. Here is Michael Williams expressing this sentiment:

Deflationism allows [one] to concede to correspondence theorists that truth is a non-epistemic notion, without compromising a functional (use-based) approach to meaning. While retaining the anti-representationalist spirit of classical pragmatism, deflationism stays closer to our ordinary use of 'true' than do accounts such as James', which threaten to elide the distinction between truth and justification. This is a real step forward. Williams (2010, p. 319)

However, deflationism about truth faces several objections that have proven to be difficult to answer. Early deflationists held that the truth predicate does not refer to a property. A.J. Ayer, for example, took himself to have shown that "the word 'truth' does not stand

\footnotetext{
5 Jaroslav Peregrin seems to agree when he says that hyperinferentialism "is clearly untenable for a language containing empirical vocabulary" (Peregrin 2012, p. 12).
} 
for anything" (Ayer 1936, p. 89). However, most contemporary deflationists now say that although there is a truth property, it is not the same kind of property as the property of being a chair or the property of being grass. They maintain that the truth property is an insubstantive property. The problem with insubstantive properties is that it is not altogether clear what exactly an insubstantive property is. Raatikainen (2006) and Douglas Edwards (2018, pp. 41-82) have, for example, argued that there is something suspicious about insubstantive properties.

Another (potentially problematic) characteristic that deflationist accounts of truth have in common is that they think that the truth property lacks explanatory powers. That is, a deflationist cannot explain certain features about our linguistic practices in virtue of the property that is denoted by truth. This is a problem for those philosophers who think that the concept of truth can help us explain certain facts. ${ }^{6}$

I do not think that these objections constitute knock-down arguments against the deflationist. ${ }^{7}$ However, many philosophers do think they are at least costs that had better be avoided. And, even more importantly, it is better if inferentialism is not tied to a particular theory about truth. For this reason, I will show in this paper that inferentialism is compatible with inflationism, without losing the core attractions of the theory. To be more precise, I will propose a version of inferentialism that (1) is compatible with antirealism about particular domains of discourse (e.g., morality), (2) supports the intuition that truth is a non-epistemic notion in some domains of discourse, (3) distinguishes between truth and justification without (4) compromising a functional (use-based) approach to meaning.

\section{Truth for Inferentialists}

Metasemantical inferentialism gives us an account of meaning, but by itself it does not tell us what it is for a sentence to be true. For the representationalist about meaning, this task seems easy. She maintains that expressions derive their meaning from how these expressions represent the world as being. So, one very plausible suggestion for the representationalist is to say that a sentence is true if and only if the world is as the sentence represents the world as being. For example, take the following sentence:

(A) The car is red.

For the representationalist, this sentence is true if and only if there is an object that "the car" refers to and this object has a specific property, i.e., the property of being red. This

\footnotetext{
${ }^{6}$ Lynch mentions the meaning of sentences and the content of beliefs as common examples of facts explained by truth-conditions (of respectively sentences and beliefs). Other facts that inflationists take to be explained by the truth property are the following truisms:

Norm of belief: it is prima facie correct to believe that $\mathrm{p}$ if and only if the proposition that $\mathrm{p}$ is true.

End of inquiry: other things being equal, true beliefs are a worthy goal of inquiry. Lynch (2009, pp. 10 \&

If these truisms should indeed be explained by the truth property, then deflationism is false. The reason for this is obvious: part of the deflationist's main thesis is that truth does not play any significant explanatory role. Deflationist typically argue that although these truisms are indeed true, they are not explained by the truth property itself (Horwich 1999, 2000). However, many inflationists think that there is a more intimate connection between truth and the norms of truth. Crispin Wright, for example, uses this connection as a motivation for preferring his truth pluralism over versions of deflationism Wright (1992).

${ }^{7}$ For other criticisms of deflationism about truth see e.g., Horisk et al. (2000) and Jago (2018, Chapter 1).
} 
seems straightforward and correct. The (global) representationalist, however, thinks that this explanation works for all sentences, e.g., she maintains that it also works for:

(B) The car is beautiful.

If (global) representationalism is true, then it is very tempting to think that this sentence is true if and only if there is an object that "the car" refers to and that this object has the property of being beautiful. All the usual metaethical options are available regarding this specific property. Aesthetic error theorists would maintain that the property of being beautiful is never instantiated, while aesthetic nonnaturalists would argue that being beautiful is a nonnatural property. What all representationalist agree on, however, is the basic assumption that in order for (B) to be true, the object that "the car" refers to should have the property ascribed by "being beautiful".

Not everyone is worried by the implications of this assumption, but the inferentialist typically is. It is, therefore, an advantage for the inferentialist that she is not committed to these implications. However, at this point we have only said what the inferentialist about truth does not say about truth. Let us now look at what an inferentialist can say about truth.

Prima facie, it does not seem very promising to combine inferentialism with an inflated truth property. At least not for an inferentialist who wants to say that both propositions consisting of narrow concepts (i.e., concepts that have their meaning determined by a set of material inferences where both the premise and the conclusion of the inferences consist of sentences only) and propositions consisting of wide concepts are capable of being true. If this inferentialist combined her view with a correspondence theory of truth, she would run into the same problems as the representationalist. She would need a "corresponding" entity or property as truth-maker; something we already saw was problematic for some concepts (such as BEAUTIFUL). However, if the inferentialist adopts an epistemic notion of truth, then she would get the strange result that concepts that have a wide inferential role have their meaning determined (in part) by an external property or entity, while the truth of these propositions does not depend on such an external object.

This is one of the reasons why inferentialists are attracted to deflationism. Typically, deflationists present their view with the help of what is sometimes called the equivalence schema: $<\mathrm{p}>$ is true if and only if $\mathrm{p}^{8}$ Given this schema, the deflationist can define her position as the claim that instances of this schema capture everything significant that can be said about truth. The deflationist can therefore say that there is nothing more to "the car is beautiful is true" then that the car is beautiful and that there is nothing more to "the car is red is true" than that the car is red. Going "deflationist", it seems therefore, avoids many of the problems that plague the inflationist accounts of truth.

But what can the inferentialist say who does not want to commit herself to deflationism? We have already established that inferentialists hold that if one articulates $p$, one commits oneself to certain other (linguistic and/or non-linguistic) elements. Matthew Chrisman suggests that we see the truth-conditions of $p$ as a way of spelling out these commitments.

The core idea [...] is that the specification of the truth conditions of a sentence should be interpreted as an articulation of what one is committed to in virtue of using the sentence to make an assertion in ordinary discursive practice. Chrisman (2016, p. 186)

\footnotetext{
${ }^{8}$ The angle brackets are used to leave open the question whether it concerns sentences or propositions.
} 
Chrisman's proposal connects the truth-conditions of a sentences with the inferential commitments one takes upon oneself when uttering the sentence. Chrisman does not tell us exactly what the connection is, or what the inferential roles are that make up the content of sentences containing 'ought'. His view is, however, compatible with the view that moral terms are "narrow" in the sense defined above. 9

So in what way could we interpret the connection between inferential networks and truthconditions? One thing that we cannot say as inferentialists is that the propositional content of a judgement is explained by the truth-conditions of that judgement (see also section 6 for a discussion of the potential tension between inferentialism and substantive notions of truth). To mitigate this problem, Chrisman seems to hold that the truth-conditions of a sentence 'depict', or model, a point in an inferential network (see also Chrisman 2016, pp. 1978, Williams 1999 and Tiefensee forthcoming). Chrisman spells this out further by arguing that 'ought' should be seen as an intensional operator with Kratzer-style truth-conditions. However, we can take the idea that truth-conditions model a point in an inferential network seriously without accepting Chrisman's other commitments.

For an alternative proposal, let us look at a moral example. Take the expression "I ought to do X". This expression is inferentially related to other expressions. It is plausible that (at least some usages of) the statement that I ought to do an action commits me to the acceptance of the utterance that it is not impermissible to do X. Also, if I ought to do X, then it is not the case that it is omissible (non-obligatory) to do X. And there are many more deontic rules that apply to the use of the expression "I ought to do X". For example, many people also believe that if we are in relevantly similar circumstances, we ought to do $\mathrm{X}$ as well. If all this is correct, then the expression's place in the inferential network can be sketched as follows:

"I ought to $\mathrm{x}$ " $\rightarrow$ "it is not impermissible to $\mathrm{x}$ "

"it is omissible to $\mathrm{x} " \rightarrow$ "it is not the case that I ought to $\mathrm{x}$ "

"I ought to x" $\rightarrow$ "If in similar circumstances, one ought to do x"

This means that asserting

(MONEY) "I ought to give the money back to Anna"

commits me to the following:

1) "it is not impermissible to give the money back to Anna"

2) "if you are in relevantly similar circumstances, you also ought to give the money back to Anna"

Moreover, the assertion that it is not omissible to give the money back to Anna commits me to the acceptance of (MONEY). If Chrisman's account of truth-conditions is on the

\footnotetext{
${ }^{9}$ In fact, Chrisman provides a book-length defense of the claim that 'ought' should be seen as an intensional operator, and proposes a modification of Kratzer-style truth-conditions. According to Kratzer, 'ought' is an intensional operator. When we add 'ought' to a sentence $S$, that complex is true just in case $S$ is true in all of the relevant possible worlds that are ranked highest according to some ordering source. The context in which 'ought $S$ ' is used fixes both the worlds that are 'relevant', and the ordering source. Chrisman suggests to expand upon this idea by providing a more fine-grained account in which not only possible worlds figure, but also possible norms. It is beyond the scope of the paper to explain the motivation and the details of this account, but Chrisman ultimately seems to rely on some version of quietism that relies on deflationism (see also Tiefensee forthcoming).
} 
right track, then these commitments are all part of the network that is modeled by the truthconditions of (MONEY). ${ }^{10}$

But this is only half of the story. For the upstream and downstream claims are also normative and connect in the same way to the truth conditions of (MONEY). Very probably, if one believes that (MONEY) is narrow in the sense described above, one takes the same stance towards the supporting normative claims. Moreover, this applies to all upstream commitments; i.e., these claims have a narrow inferential role as well. If this is correct, then we never get "outside" the moral language game when spelling out the conditions under which (MONEY) is true. ${ }^{11}$ Let us suppose that the above is correct for the moral domain. Then the truth-conditions of moral claims model a position in an inferential network that consists only of other sentences. ${ }^{12}$ More generally, for domains of discourse that have a narrow inferential role, the truth-conditions of a sentence model its position in an inferential network that consists only of other sentences. If we combine this with the assumption that every sentence stands in inferential relations to at least one other sentence (which is one of the inferentialist's key commitments), we get a pattern that is recognizable. For, the sentences that are the truth-conditions of a sentence have sentences as truth-conditions as well. And this structure, which has no room for robust entities as truth-conditions, is compatible with an epistemic notion of truth. ${ }^{13}$

\footnotetext{
${ }^{10}$ If we accept Chrisman's proposal that "ought" functions as a modal operator, the story becomes slightly more complex. The results are, however, similar. To see why this is so, let us take the claim
}

$(\mathrm{OH})$ "We ought to do more to help the poor".

Simplified a little, Chrisman suggests to first distill the imperative-like content of $(\mathrm{OH})$ (something like "let's do more to help the poor"). Given this imperatival content, we can say that $(\mathrm{OH})$ is true just in case, in the relevant worlds, the best norms require satisfaction of the imperative (Chrisman 2016, p. 147) (see the previous footnote for more details of Chrisman's account). This is easily interpreted in a representationalist manner which would commit us to realism about norms and possible worlds. However, this is not how a nonrepresentationalist inferentialist would like to see matters. Chrisman prefers to interpret the truth-conditions as a description of the position in a network of inferentially related commitments one takes upon oneself when uttering $(\mathrm{OH})$.

These commitments run in two directions. Downstream, one is committed to "intentions to act [...] in ways that comply with the imperatival content" (Chrisman 2016, pp. 197-8). So if one utters (OH), one is committed to intend to help the poor (in particular contexts). Moreover, when one is challenged after uttering $(\mathrm{OH})$. One might defend $(\mathrm{OH})$ "by appealing to more general normative claims that support the norms relative to which the imperatival content is legitimate at the contextually relevant worlds" (Chrisman 2016, p. 198).

What is important, is that even if we interpret 'ought' as a modal operator, the up- and downstream commitments consist of "narrow" content.

11 My use of the label "the moral language game" is supposed to include connections to intentions and desire-like states. See also Sinclair (2017, pp. 105-6) for a discussion of this point.

12 It might be thought that talk of truth-conditions automatically commits one to an inflationist notion of truth. However, this would be mistaken, as a deflationist reading of truth-conditions is also available to deflationists. For Hartry Field, the equivalence schema ( $<\mathrm{p}>$ is true if and only if $\mathrm{p})$ is just to say that "p" has the truth-conditions that $\mathrm{p}$. The expression "the car is red" has, for example, the truth-conditions that the car is red (Field 1994). (See for a discussion e.g., Boghossian (1990), Kraut (1993), O'Leary-Hawthorne and Price (1996) and Williams 1999, 2010).

13 Strictly speaking, the epistemic notions of truth, such as the coherence theory, are not committed to sentences being the bearers of truth. But once we have established what the bearers of truth are (propositions, beliefs, sentences), the coherence theorist holds that the truth-conditions of these truth-bearers consists in its coherence with other truth-bearers (Young 2018). This contrasts with a correspondence theorist, who holds that the truth-conditions of the truth-bearers are objective features of the world. 
One word of caution. I say that it is compatible with an epistemic notion of truth, because I do not think the inferentialist is committed to this claim. An inferentialist could also have more 'relaxed' or 'quietist' inclinations. She would then combine the claim that truthconditions model a place in an inferential network with the claim that only one way of doing this is correct (perhaps even with the claim that only one option corresponds (in a deflated way) to reality). I think this is what Christine Tiefensee has in mind when she argues that "relaxed realists" should embrace inferentialist metaconceptualism Tiefensee (forthcoming). However, what the above shows is that for domains of discourse that have a narrow inferential role, inferentialism is compatible with the claim that expressions are true in virtue of some epistemic notion of truth.

In this paper I do not want to argue that a particular epistemic notion of truth is most plausible for the moral domain. Let us, therefore, just borrow a page or two from truth pluralists such as Crispin Wright and Michael Lynch, and focus on what they take to be a plausible contender for this domain: superwarrant. Epistemic notions of truth often build truth upon warrant. Inspired by Charles Sanders Peirce, we can say that given a specific definition of warrant, moral judgement $\mathrm{P}$ is superwarranted if and only if it is warranted at some stage of inquiry and would continue to be warranted through every successive improvement.

Superwarrant: The belief that $\mathrm{p}$ is superwarranted if and only if the belief that $\mathrm{p}$ is warranted without defeat at some stage of inquiry and would remain so at every successive stage of inquiry. Lynch (2009, p. 38)

Let us use superwarrant as the epistemic notion of truth for domains of discourse that have a narrow inferential role. For the inferentialist, a belief is warranted without defeat if one is entitled to the downstream commitments of that belief. If this would remain the case at every successive stage of inquiry, then it is also superwarranted. This makes the notion of superwarrant especially suitable for narrow domains (which does not mean that the inferentialist is committed to this notion of truth). In this example I just assumed that the moral domain is a domain that has narrow inferential role, but nothing in my argument hangs on that. As we will see later, the only thing I need in my argument is that there are domains of discourse in which all terms have a narrow inferential role.

We have, until now, focused on domains of discourse in which all terms have a narrow inferential role. Many inferentialists think that there are such domains. However, as we saw above, many inferentialist also believe that there are domains of discourse for which this does not hold. The paradigmatic example of such a domain is the scientific domain. It is widely accepted that the meaning of some scientific terms is determined by so-called wide rules. Observational terms are typical examples.

If this is correct, then the inferential network that is modelled by the truth-conditions of the expression "the car is red" does not only contain sentences such as:

(1) "the car is coloured"

(2) "the car is not completely yellow"

but also something that takes us outside the realm of language. The inferential network of the expression "the car is red" contains elements that are non-linguistic: that the car has the property of being red. This extra-linguistic entity that figures in the inferential role of 
the term red, forces a connection between the linguistic expression and the outside world. "The car is red" can only be true if the car has the property of being red. ${ }^{14}$

Furthermore, if we investigate the term "car", we will find out that the wide role of this term makes it the case that "the car is red" can only be true if there is an object that "the car" refers to and that this object has the property of being red. In this fashion, we have reached a notion of truth which requires that an expression is true if and only if it corresponds to reality.

To recapitulate, if inferentialism is correct, the meaning of expressions is determined by their inferential role. These inferential roles are narrow for some domains of discourse, and wide for other domains. In domains where all terms have a narrow inferential role, the inflationist can plausibly hold that an expression is true if it has an epistemic property (such as superwarrant). In domains where some terms have a wide inferential role, an expression's truth is determined by the question whether it has the property "corresponds to reality".

This conclusion relies on Chrisman's suggestion that the truth conditions of a sentence model what one is committed to in virtue of asserting that sentence. If truth-conditions are articulated by inferential rules, and a specification of the inferential rules never relies on reference to anything non-linguistic, then what it takes for a sentence to be true does not involve anything non-linguistic either. If this is correct, then expressions that have a narrow conceptual role are true in virtue of having an "epistemic" property.

\section{Truth Pluralism and the Referent of "True"}

In the previous section we concluded that in domains where all terms have a narrow inferential role, it is an epistemic notion (such as superwarrant) in virtue of which propositions are true. In domains where this is not the case, it is a relation such as correspondence in virtue of which propositions are true. Combined with the plausible assumption that there are domains in which all terms have a narrow inferential role and terms that lack this feature, we have a version of truth pluralism. If this is correct, inferentialism is compatible with a version of truth pluralism: there are different substantive properties in virtue of which propositions are true, e.g. correspondence or superwarrant.

Although I have argued that inferentialism is compatible with truth pluralism, I have not said anything definitive on the referent of the truth predicate. In this section I will show that the best way of spelling out truth pluralism is compatible with the inferentialist's core commitments. All truth pluralists agree that there is a range of (alethically potent) properties in virtue of which judgements are true.

Early truth pluralists believed that we do not need a property in addition to these properties as referent for the truth predicate. It could be the case that the term "true" refers to different properties in different domains. For example, suppose that in the empirical domain,

\footnotetext{
${ }^{14}$ I take Chrisman to make the same point when he argues that inferentialism doesn't "commit us to the idea that language use is merely a 'game' of giving and asking for reasons" (Chrisman 2016, p. 191; emphasis in original). Just as in my example above, he thinks that it is plausible that someone who asserts that grass is green is "inferentially committed to the proposition that grass has the (real, mind-independent, describable) property of being green." Chrisman continues by stating that if "this were right about this sentence or any other class of sentences, inferentialism might be seen as overlapping with the core representationalist idea outlined earlier but as also offering a deeper explanation of the relevant phenomena" (Chrisman 2016, p. 192). My contention of course is that there is overlap for those domains that are "wide" in the sense describe above.
} 
judgements are true in virtue of corresponding to reality and that moral judgements are true in virtue of cohering with other moral judgements. Then it could be that "true" refers to correspondence in the empirical domain, and to superwarrant when used in the moral domain. ${ }^{15}$

Recently, however, truth pluralists have recognized that there are several problems with such a view. ${ }^{16}$ In light of these problems, contemporary truth pluralists reject the idea that we do not need a property in addition to these properties as referent for the truth predicate. Instead, they adopt the position that "true" denotes exactly one substantive property, while holding that there are different properties in virtue of which judgements are true. They believe that truth is in some important sense "one and many". Below we can find Pedersen and Edwards summarizing Lynch's take on this issue:

Truth as one and many (TOM): A satisfactory account of truth must characterize truth both as one and many. It must be of a mixed sort, incorporating simultaneously the monist idea that there is a truth property possessed by any true proposition (whatever its domain) and the pluralist idea that propositions can possess this truth property in virtue of having one among a range of "alethically potent" properties (correspondence, supercoherence, etc.). Pedersen and Edwards (2011, p. 215)

So, many truth pluralists think that a "pure" pluralist view, i.e., a pluralist view that only recognizes the pluralistic aspect of truth, faces many problems that are difficult to overcome.

\footnotetext{
15 There are different possible additional stories about why it is the case that "true" refers to different properties. It could be that "true" is ambiguous just like "bank" is. A different, and slightly more plausible, view is that "true" is a definite description that refers to different properties in different contexts. This is the view that Lynch ascribes to Crispin Wright (Lynch 2009, p. 60-2). Wright denies that we should interpret him in that way.

16 One of the best-known objections to this view is that it suffers from the mixed inferences and validity problem (Tappolet 1997, pp. 209-10; Lynch 2009, p. 55-6). The problem can be presented as follows. Suppose that "it is true that winter is coming" means that "winter is coming" has the property of corresponding to reality. Suppose furthermore that "it is true that you ought to build a higher wall" means that "you ought to build a higher wall" has the property that it coheres with other moral beliefs. Can we still say that the following argument is valid?
}

(P1) If winter is coming, you ought to build a higher wall.

(P2) Winter is coming.

(C) You ought to build a higher wall.

Most philosophers believe that being truth-preserving is a necessary condition for validity. This implies that for the argument to be valid, it has to be the case that if (P1) and (P2) are true, (C) is also true. However, as truth for the second premise and for the conclusion are different properties, there is not a single property that is being preserved. Truth pluralists who maintain that the term "true" refers to different properties in different domains of discourse should therefore give a different story about validity. That position is not very attractive.

The second problem with the "simple" version of truth-pluralism is the complex sentences problem. The problem is that it is not clear what it means to say that (P1) is true. The antecedent and the consequent are from domains in which the term "true" refers to different properties. So to what property does "true" refer when applied to the whole premise? The answer that the whole premise is true if it is not the case that the antecedent is true while the consequent is not, is not acceptable. Critics maintain that this answer is question-begging. What we really want to know is when the conditional itself is true (Lynch 2009, p. 56-7).

A third, and related, potential problem for versions of truth pluralism has to do with the fact that we can use the concept of truth to make blind generalizations. In an overly optimistic mood I could say that everything in this paper is true. But this paper contains claims from different domains of discourse. So if we take "true" to be ambiguous, which meaning of "true" do I have in mind when I make the bold assertion about the content of this paper? This is a question that many versions of truth pluralism cannot give an adequate answer to (see (Lynch 2009, p. 56-7) for a discussion of this problem). 
Michael Lynch, for example, is a truth pluralist who feels the force of the arguments against original truth pluralist view. He proposes, therefore, that there is an additional, substantial property that the truth predicate refers to.

According to Lynch, the truth property $(\mathrm{T})$ has a number of essential features, say E. We have already established that there is a set of properties in virtue of which judgements in different domains of discourse are true. Lynch now proposes that these properties manifest truth in the different domains. For Lynch, "manifest" is a technical term that is defined as follows: property $\mathrm{F}$ is manifested by property $\mathrm{M}$ if "it is a priori that F's essential features are a subset of M's features" (Lynch 2009, p. 74). So, it is a priori that the essential features of the truth property are a subset of the features of correspondence, superwarrant etc. This allows Lynch to combine the monist idea that there is a truth property possessed by any true proposition (whatever its domain) and the pluralist idea that propositions can possess this truth property in virtue of having one among a range of "alethically potent" properties (correspondence, supercoherence, etc.).

So what are the essential features of truth that are manifested by the different alethically potent properties? According to Lynch, the essential features can be divided into two parts. Firstly, the truisms about truth have to be included. For example, that it is prima facie correct to believe that $\mathrm{p}$ if an only if the proposition that $\mathrm{p}$ is true, is for Lynch an essential feature of truth. And the same holds for other truisms, such as End of Inquiry. This allows him to explain the truisms about truth. Secondly, if a version of truth pluralism is true, then the fact that there is a range of properties in virtue of which expressions are true, is also one of the core features of truth. If we combine these two parts, then we get the conclusion that truth refers to a substantial property that has as essential features (1) features that are a priori (the truisms) and (2) features that have to be discovered by studying the concept of truth (such as the fact that there is a range of properties in virtue of which expressions are true, if that is a fact).

And there is no reason why the inferentialist who does not want to commit herself to deflationism about truth couldn't also make use of this property as a referent for truth. This position would allow the inferentialist to claim that propositions consisting of narrow concepts and propositions consisting of wide concepts are capable of being true. For those propositions have that property that has among its essential features the platitudes about truth. The upshot, of course, is that this position does not suffer from the problems that plague the original truth pluralist view, and avoids the problems that plague deflationism.

\section{Advantages of Inferentialist Truth Pluralism}

To wrap up, let us assess inferentialist truth pluralism. This assessment consists of two parts: we have to see whether the position is attractive to inferentialists and show that it has advantages over deflationism.

We can see that inferentialist truth pluralism meets many of the characteristics that Williams takes to be attractions of deflationism. First of all, inferentialist truth pluralism allows one to concede to correspondence theorists that truth is a non-epistemic notion (in the relevant domains). For, the inferentialist truth pluralist not only holds that the truth predicate refers to a substantive property. She also maintains that in domains of discourse where the meaning of terms is determined by wide inferential roles, an expression's truth is determined by the question whether it has the property "corresponds to reality".

Secondly, it still is a functional (use-based) approach to meaning. This might need some explanation, as there is a prima facie tension between use-based theories of meaning and 
substantive theories of truth. Typically, when one allows for a substantive theory of truth, this theory also plays an important explanatory role in the theory of meaning. And this is at odds with the inferentialist's main claim that meaning is determined by inferential role. However, the proponent of a substantive theory of truth does not have to hold that truth plays an explanatory role in the theory of meaning. She can allow for the truth property to explain the normativity of truth talk: e.g., that it is prima facie correct to believe that $\mathrm{p}$ if and only if the proposition that $\mathrm{p}$ is true and that other things being equal, true beliefs are a worthy goal of inquiry (Lynch 2009, pp. 10 \& 12). This is, however, compatible with truth not playing an explanatory role in the theory of meaning. (another position that combines a use-based theory of meaning with a substantive theory of truth can be found in Wedgwood 2001, 2007, 2017).

So inferentialism is compatible with substantive theories of truth, but we might still worry that a use theory of meaning is redundant if we already have a substantive notion of truth. A critic could argue as follows. Given that you adopt a substantive notion of truth, doesn't that mean that TRUE is a wide concept? And, if TRUE is a wide concept, can't we just explain meaning in terms of the truth-conditions we are tracking? I think that there are two ways to respond to this objection. Firstly, if we could explain meaning in terms of truth, then this wouldn't mean that we should do so. There might be (and probably are) other reasons to hold on to a use theory of meaning. Secondly, theorists who explain meaning in terms of truth, typically rely on the correspondence theory of truth. Remember that the property that Lynch takes to be possessed by any true proposition is a rather thin property. It consists of the truisms about truth and some claims such as the claim that there is a range of properties in virtue of which expressions are true. It still has to be shown that such a thin property can, just as the correspondence theory, be used to explain meaning.

And finally, inferentialist truth pluralism allows us to distinguish between truth and justification in all domains of discourse. Even in domains where we have an epistemic notion of truth, the availability of superwarrant allows us to distinguish between beliefs that are true, and beliefs that are (merely) justified. A belief that is superwarranted, is not only justified at some stage of inquiry, but it would remain so at every successive stage of inquiry.

So I take myself to have shown that inferentialist truth pluralism has many of the characteristics that Williams takes to be attractions of deflationism. Moreover, the view also avoids some of the problems of deflationist inferentialism. Firstly, it is not committed to an insubstantive truth property. In line with the TOM-approach, there is a substantial property that the truth predicate refers to. Secondly, it allows us to use the notion of truth to explain the normativity of truth talk. For example, Michael Lynch takes the fact that it is prima facie correct to believe that $\mathrm{p}$ if and only if the proposition that $\mathrm{p}$ is true and that other things being equal, true beliefs are a worthy goal of inquiry to be essential properties of the truth property. If these properties are essential properties of the truth property, it is easy to explain the normativity of truth talk.

So we have seen that inferentialist truth pluralism is attractive to antirealist inferentialists who do not want to be committed to deflationism. But is there only good news for the antirealist inferentialist? As usual, this depends. For giving up deflationism does come with some costs. Inferentialist truth pluralism does give us a non-epistemic notion of truth in some domains - those with wide inferential role. But domains with a narrow inferential role are left with an epistemic notion of truth. And this will be unsatisfying to some inferentialists. However, as we have seen above, the position I advocate also has some advantages over the current dominant versions. Moreover, although superwarrant does not give us the kind of objectivity that moral realists are typically looking for, many metaethicists hold that 
the same is true for metaethical positions that rely on deflationism. ${ }^{17}$ So I hope that at least for some inferentialists, the advantages of the view allow it to be a serious alternative to the currently dominant antirealist versions of inferentialism.

\section{Conclusion}

I have argued that metasemantic inferentialism is compatible with truth pluralism. In domains of discourse where all terms have their meaning determined by narrow inferential roles, the inferentialist can argue that sentences are true in virtue of an epistemic notion of truth (such as superwarrant), while sentences are true in virtue of a property such as correspondence in domains where some terms have their meaning determined by a wide inferential role. Combined with the plausible premise that both types of domains actually exist, it is tempting to conclude that truth has a pluralist nature. At the very least, inferentialists are not committed to deflationism. This adds to the attractiveness of inferentialism. Moreover, I have presented Michael Lynch's specific version of truth pluralism and have shown that this version is also compatible with inferentialism.

Open Access This article is licensed under a Creative Commons Attribution 4.0 International License, which permits use, sharing, adaptation, distribution and reproduction in any medium or format, as long as you give appropriate credit to the original author(s) and the source, provide a link to the Creative Commons licence, and indicate if changes were made. The images or other third party material in this article are included in the article's Creative Commons licence, unless indicated otherwise in a credit line to the material. If material is not included in the article's Creative Commons licence and your intended use is not permitted by statutory regulation or exceeds the permitted use, you will need to obtain permission directly from the copyright holder. To view a copy of this licence, visit http://creativecommonshorg/licenses/by/4.0/.

Acknowledgments The author is grateful to Daan Evers, Bart Streumer and two anonymous reviewers from Ethical Theory and Moral Practice for providing valuable comments on previous versions of the paper.

\section{References}

Ayer AJ (1936) Language, truth and logic. V. Gollancz, London

Boghossian PA (1990) The status of content. Philos Rev 99(2):157-84. https://doi.org/10.2307/2185488

Brandom R (1994) Making it explicit: Reasoning, representing, and discursive commitment. Harvard University Press

Brandom R (2000) Articulating reasons: An introduction to inferentialism. Harvard University Press

Brandom R (2007) Inferentialism and some of its challenges. Philos Phenomenol Res 74(3):651-676

Chrisman M (2011) Expressivism, inferentialism and the theory of meaning. In: Brady M (ed) New Waves in Metaethics. Palgrave Macmillan, London, pp 103-125. https://doi.org/10.1057/9780230294899_6

Chrisman M (2016) The meaning of 'ought': Beyond descriptivism and expressivism in metaethics. Oxford University Press, USA

Dutilh Novaes C, Veluwenkamp H (2017) Reasoning Biases, Non-Monotonic Logics and Belief Revision. Theoria 83(1):29-52

Edwards D (2018) The metaphysics of truth. Oxford University Press

Enoch D (2011) Taking morality seriously: A defense of robust realism. Oxford University Press

Field H (1994) Deflationist views of meaning and content. Mind 103(411):249-285

Geach PT (1965) Assertion. The Philosophical Review 74:449-465

Horisk C, Bar-On D, Lycan WG (2000) Deflationism, meaning and truth-conditions. Philos Stud 101(1):128. https://doi.org/10.1023/A:1026463916160

\footnotetext{
${ }^{17}$ See for example Veluwenkamp (2017).
} 
Horwich P (1999) The minimalist conception of truth. In: Blackburn S, Simmons K (eds) Truth. Oxford University Press

Horwich P (2000) Norms of truth and meaning. R Inst Philos Suppl 47:19-34

Jago M (2018) What truth is. Oxford University Press, Oxford

Korsgaard CM, O'Neill O (1996) The sources of normativity. Cambridge University Press

Korsgaard CM (2009) Self-constitution: Agency, identity, and integrity. Oxford University Press

Kraut R (1993) Robust deflationism. Philos Rev 102(2):247-263. https://doi.org/10.2307/2186039

Loar B (2006) Language, thought, and meaning. In: Devitt M, Hanley R (eds) The Blackwell Guide to the Philosophy of Language. Blackwell Publishing, Malden

Lynch MP (2009) Truth as one and many. Clarendon Press

O'Leary-Hawthorne J, Price H (1996) How to stand up for non-cognitivists. Australas J Philos 74(2):275292. https://doi.org/10.1080/00048409612347251

Pedersen NJLL, Edwards D (2011) Truth as one(s) and many: On lynch's alethic functionalism. Anal Philos 52(3):213-230

Peregrin J (2012). In: Gurova L (ed) What is inferentialism?. Cambridge Scholars Pub., Cambridge. https:// books.google.nl/books?id=n0gsBwAAQBAJ

Price H, Blackburn S, Brandom R, Horwich P, Williams M (2013) Expressivism, pragmatism and representationalism. Cambridge University Press, Cambridge. https://www.cambridge.org/core/books/ expressivism-pragmatism-and-representationalism/F62F34DF16B22CD68A5D045999D782F7

Raatikainen P (2006) Problems of deflationism. In: Aho T, Pietarinen A-V (eds) Truth and Games in Logic and Language, vol 78. Acta Philosophica Fennica, pp 175-185

Searle JR (1962) Meaning and speech acts. Philos Rev 71:423-432

Sinclair N (2017) Conceptual role semantics and the reference of moral concepts. Eur J Philos (1):95-121

Tappolet C (1997) Mixed inferences: A problem for pluralism about truth predicates. Analysis 57(3):209210

Tiefensee C (2016) Inferentialist metaethics, bifurcations and ontological commitment. Philos Stud 173(9):2437-2459. https://doi.org/10.1007/s11098-015-0622-y

Tiefensee C (forthcoming) Metasemantics for the relaxed. In: Shafer-Landau R (ed) Oxford Studies in Metaethics, vol 16

Veluwenkamp H (2017) Parfit's and Scanlon's Non-Metaphysical Moral Realism as Alethic Pluralism. Ethical Theory and Moral Practice 20(4):751-761

Warren MD (2015) Moral inferentialism and the frege-geach problem. Philos Stud 172(11):2859-2885. https://doi.org/10.1007/s11098-015-0447-8

Wedgwood R (2001) Conceptual role semantics for moral terms. Philos Rev 110(1):1-30

Wedgwood R (2007) The nature of normativity. Oxford University Press

Wedgwood R (2017) The value of rationality. Oxford University Press

Williams M (1999) Meaning and deflationary truth. J Philos 96(11):545-564. https://doi.org/jphil19999 61139

Williams M (2010) Pragmatism, minimalism, expressivism. Int J Philos Stud 18(3):317-30

Wright C (1992) Truth and Objectivity. Harvard University Press

Young JO (2018) The coherence theory of truth. In: Zalta EN (ed) The Stanford Encyclopedia of Philosophy. Fall 2018. Metaphysics Research Lab, Stanford University

Publisher's Note Springer Nature remains neutral with regard to jurisdictional claims in published maps and institutional affiliations. 